\title{
Comentarios en la presentación del libro Ixcan: Masacres y Sobrevivencia, cuarto volumen de la serie Al atardecer de la vida, de Ricardo Falla
}

\section{Andrés Cabanas}

¿Cómo podemos definir este cuarto volumen de la colección $\mathrm{Al}$ atardecer de la vida? ¿De qué nos habla Ricardo Falla? ¿Sobré qué nos invita a pensar y reflexionar? Masacres

$\mathrm{y}$

sobrevivencia, el volumen que hoy se presenta en la capital, es el registro pormenorizado de una época en la que se institucionalizó la barbarie o, dicho de otro modo, en la que la barbarie hecha Estado impuso un ciclo de violencia y muerte que todavía no termina. Violencia y muerte ejecutadas con una racionalidad política implacable e impecable.

La obra es, además, un esfuerzo de continuidad en el conjunto de escritos de Ricardo Falla, al matizar, profundizar, ampliar y, si es

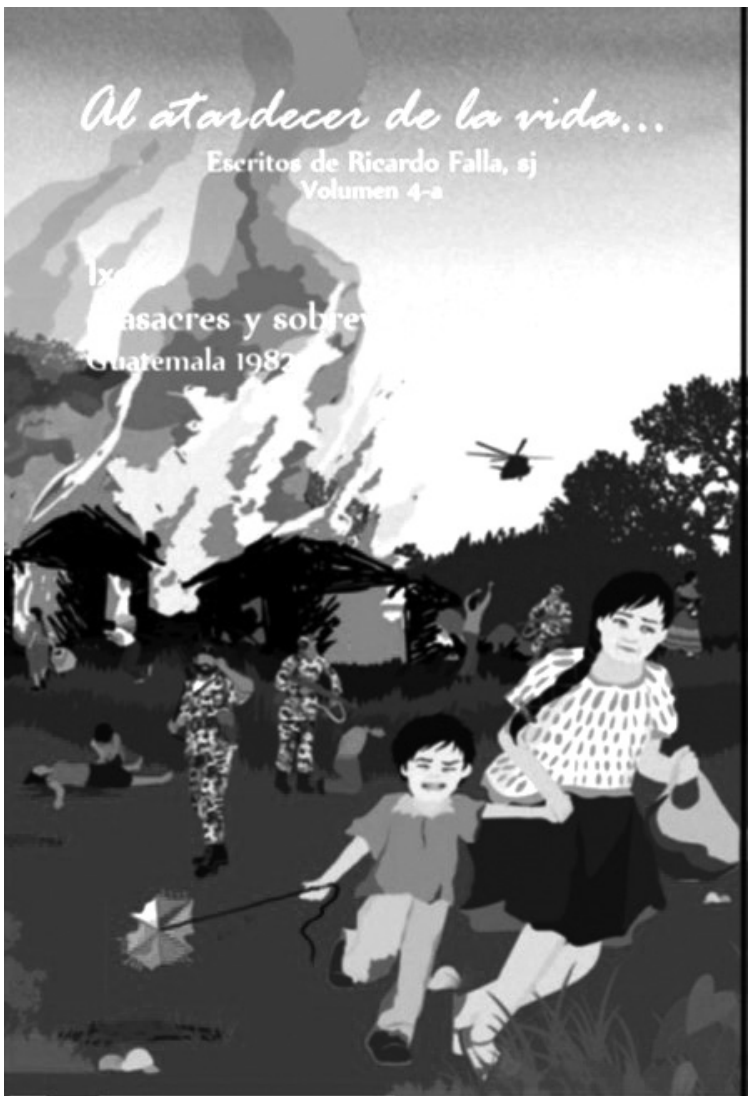

Instituto de Investigación y Proyección Social sobre Dinámicas Globales y Territoriales - IDGT de la Vicerrectoría de Investigación y Proyección (VRIP), Universidad Rafael Landívar, Guatemala. 
necesario, cuestionar argumentos precedentes, en un ejercicio crítico y autocrítico que responde a la concepción de la investigación como aproximaciones sucesivas a una verdad siempre parcial, siempre escurridiza.

Es, en tercer lugar, una obra necesaria para conocer lo que sucedió e intentar evitar que se repita: en este país donde, al contrario de lo que expresaba Mario Payeras, "la memoria no dispone de un vasto mapa".

Masacres y Sobrevivencia es, en fin, un relato riguroso, fiel a los hechos, voluntaria o aparentemente frío y distante, pero humano en su enormidad. Una descripción sumamente densa, en ocasiones insoportable, de "crudezas y crueldades sin cuento", hasta cierto punto "denigratoria y negativa", como reconoció el autor en la introducción de Masacres de la Selva.

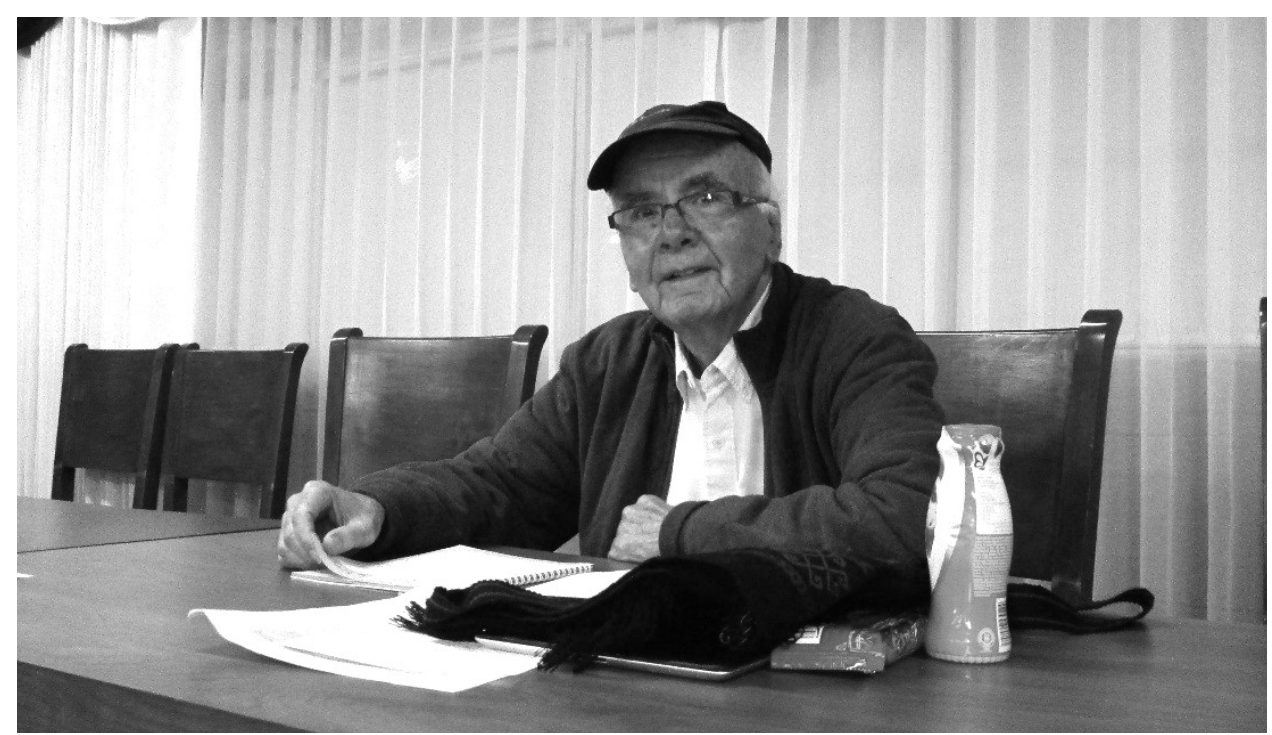

Ricardo Falla presentando su obra en el Campus de Quetzaltenango de la Universidad de San Carlos, durante el Segundo Congreso de Estudios Mesoamericanos, Quetzaltenango, Guatemala.

Foto: José Luis Rocha

Pero el alcance de la obra no se detiene aquí. Ricardo Falla se esfuerza en registrar sentimientos que humanizan el relato en medio del terror, la impunidad y la muerte. Sobre estos sentimientos el autor pregunta, indaga, lo imagino repreguntado y escribiendo en cuadernos con letra apretada y clara, para finalmente describir e interpretar. Un testigo del Centro Nueva Concepción, afirma que durante las masacres, siente "despreocupación, apresuramiento, miedo, preocupación, atracción al lugar de los hechos".

Otro testigo, de Cuarto Pueblo, describe cómo el susto se convierte en "miedo, después en tristeza, al constatar los que murieron. La tristeza genera el llanto y el recuerdo de los momentos felices idos". Estos ejemplos se repiten y analizan durante páginas enteras a lo largo de la obra.

Pero la antropología o la etnografía del sentimiento que realiza Falla no solamente refleja ansiedad, preocupación, angustia, terror. Uno de los testigos principales de la masacre del Centro San Luis relata que, mientras permanece escondido y asustado 
observando la presencia del Ejército, "hay momentos en que el ánimo se le distrae y se ríe al observar el miedo de algunos soldados".

Entonces nos preguntamos: ¿es posible la humanidad, la ternura, el cariño, la compasión, en medio de la violencia extrema? ¿Es posible reírse cuando a tu alrededor los soldados - pido disculpas anticipadas por la cita literal y brutal- "tiran gente adentro de las construcciones quemadas, juegan como pelotas con los hombres, los dejan al sol y después los tiran en la escuela vieja que estaba en fuego, mientras a las mujeres las tiran como en horno" (Cuarto Pueblo). La historia, los testigos y Ricardo Falla nos dicen: sí es posible la ternura.

Masacres y Sobrevivencia puede leerse entonces como el necesario recuentorecuerdo de la violencia, para enseñanza de víctimas y victimarios (que no hay modo que aprendan), pero también en clave del golpe emocional, como el propio autor lo describe. El golpe emocional de la brutalidad y crueldad. El golpe emocional de la humanidad, la risa y la ternura. El golpe emocional de la esperanza.

Un organizador de la resistencia relata que, para evitar que la población regrese a buscar a sus familiares muertos y se exponga a ser masacrada, tiene que cortar de raíz toda posibilidad de sobrevivencia, diciendo a los vivos que es imposible que sus familiares hayan resistido las masacres. El testigo "corta la esperanza" para que pueda desarrollarse el proceso de huida: es decir, la esperanza de la salvación y de una nueva vida. Terror y esperanza, al mismo tiempo, en un plano idéntico, sin transición.

La humanidad y la esperanza, todavía en los intersticios de la violencia física y simbólica de la que no logramos liberarnos, otorga a la obra de Falla, parafraseando a Adolfo Gilly, un carácter de epocal: relato del genocidio y la destrucción, así como de sacrificios, renuncias, sueños y utopía. En este sentido, Masacres y Sobrevivencia, y la obra completa de Falla, no cierra un relato sino abre inquietudes y reflexiones, que la convierten en reflejo de una época y aporte para el momento actual.

Hoy, 2016, no estamos en el mismo momento en que sucedieron las masacres, ni cuando se escribió la obra. Ahora, nuevas y viejas generaciones se indignan, cuestiona, protestan, recuperan espacios y valores colectivos, derriban gobiernos, caminan durante doce días para decir Estamos aqui y no pueden decidir sin nosotros/as, sueñan con la posibilidad de un nuevo país. En cierto sentido, intentamos hacer la transición de la guerra a la paz que no pudimos en 1996, temporalmente derrotados por la agenda neoliberal, las mesas de diálogo y nuestras desarticulaciones internas. 


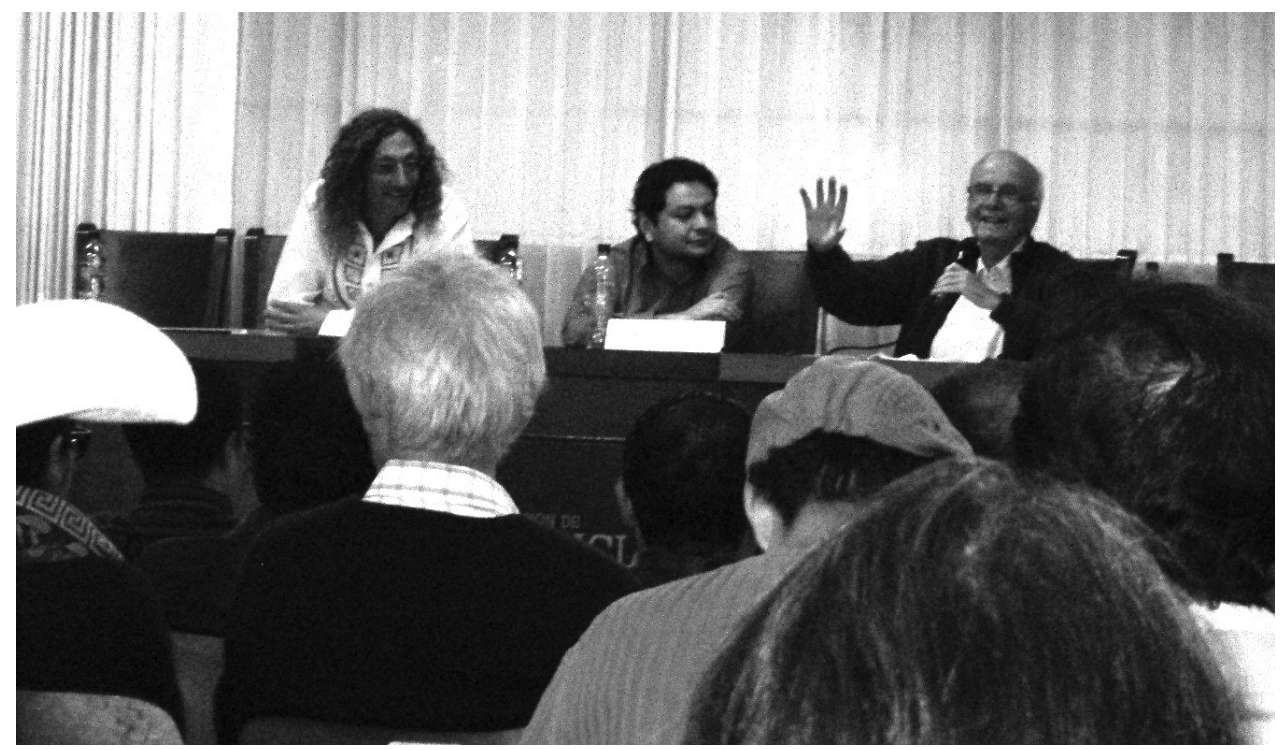

Conversatorio "Guerra en Colombia y Guatemala". Falla presentando en el campus de Quetzaltenango de la Universidad de San Carlos, Guatemala. Junto a él: Sergio Palencia y Manuel Rozental. Foto: José Luis Rocha

Este libro de Ricardo y su obra completa nos recuerdan que la esperanza, siempre matizada de contradicciones y tensiones, es posible y necesaria, cuando va acompañada de la memoria exacta de nuestra historia.

Finalizo con un texto de Mario Payeras, autor que no me cuesta emparentar con Ricardo Falla y que creo logra definir las características del escritor y de la persona:

Sobre las tres grandes vocaciones

Hoy sabemos que el regreso a las primaveras idas es irrealizable; que el hábito de explicarse las cosas acalambradas de contradicciones es la fuente de toda lucidez; y que el oficio de conspiradores para cambiar el mundo es la única manera de no envejecer. 